\title{
Information Literacy Instruction in Canadian Academic Libraries: Longitudinal Trends and International Comparisons
}

\author{
Heidi Julien
}

A national survey of information literacy instruction in Canadian academic libraries revealed that trends in teaching objectives, methods, and content have changed little in the past five years. Instructional librarians continue to face numerous challenges, particularly with regard to limited resources and faculty and student attitudes. Although more than half of the libraries believe they are meeting their instructional objectives, only a minority actually record their objectives formally and evaluation of instructional success remains mostly informal. Findings from the survey are compared with an earlier Canadian study and with similar work done in the United States and New Zealand.

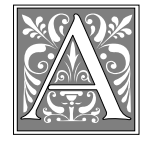

lthough much has been made in the research and professional literature about the value of information literacy instruction in academic libraries, it is at the level of practice that evaluation of learning outcomes begins. To provide a framework for a future attempt at assessing the outcomes of instruction in Canadian academic libraries, the instructional objectives, practices, and opinions of instructional librarians were analyzed. The analysis is longitudinal, noting trends over a five-year period and making comparisons with a similar analysis done in New Zealand. In addition, published data from a recent U.S. study are compared with the Canadian data. For practitioners, the data presented may be useful for benchmarking their own instructional activities. From the perspective of re- searchers interested in analyzing information literacy as a concept, understanding how theory is translated into practice in the real world of budget restraints and ambivalent campus cultures is a necessary complement to their endeavors.

\section{Methods}

Ethical approval for the study was provided by Dalhousie University. In January 2000, a written questionnaire was sent to all university and college libraries in Canada ( $n=408$ ). In Canada, colleges (or community colleges) are typically small academic institutions that award job-related diplomas in technical subjects. For institutions having more than one library, a survey was sent to each library on campus. The cover letter was directed to the librarian having primary responsibility for instruction at that library so as to en-

Heidi Julien is in the School of Library and Information Studies, Faculty of Management, at Dalhousie University; e-mail: hjulien@is.dal.ca. 
sure that respondents had the adequate background and understanding to answer questions accurately. Respondents were assured of anonymity, both as individuals and for their institutions. Surveys were sent in English to libraries at English-language institutions and in French to libraries at French-language institutions. Of 309 English surveys sent, 168 were returned, for a response rate of 54 percent. Of ninety-nine French surveys sent, thirty-nine were returned, for a response rate of 39 percent. The overall response rate was 51 percent, so it is assumed that the data are reliable. The questionnaire included closed-response items, which were analyzed quantitatively. Written comments to open-ended items were analyzed and, using content analysis, grouped into categories where warranted. Representative comments are quoted verbatim to illustrate commonly expressed themes and viewpoints.

First-year students are a focus of instruction at 84.6 percent of libraries, undergraduates at 59.1 percent of libraries, and returning adult students at 40.4 percent of libraries.

The survey items sought responses on the following topics:

- institutional data (type, size, technological sophistication);

- types of instruction provided (i.e., whether there is a formal instructional program);

- resources devoted to instruction (human, financial, encouragement);

- methods of instruction;

- content of instruction (i.e., for which resources and services);

- focus of instruction (i.e., to which client groups);

- effect of information technology on instructional content and methods;

- objectives of instruction (both actual and ideal);

- evaluation of instruction;

- opinions about the definition of information literacy (respondents were provided with potential elements drawn from a wide range of published literature on information literacy and asked whether they agreed);

- opinions about librarians' degree of responsibility for teaching information literacy skills;

- barriers faced by instructional librarians.

Because this survey was based on one done in 1995 by Heidi Julien and Gloria J. Leckie, longitudinal trends in instruction in Canadian academic libraries can be discerned. ${ }^{1}$ In addition, this analysis makes international comparisons with the results of a survey of instruction in New Zealand academic libraries done in $1997 .^{2}$ And finally, this analysis includes comparisons with data collected in the United States in 1995. The most recently published comparable national data on instruction in the United States appear to be from Linda Shirato and Joseph Badics's report of the 1995 LOEX survey. ${ }^{3}$ Because the U.S. data, like the Canadian data, were collected in 1995, the results of these two surveys are most strictly comparable. However, care must be taken in interpretation of the U.S. results because the response rate for the LOEX survey was only 35 percent.

\section{Results and Discussion Respondents}

Table 1 shows the proportions of survey respondents from libraries serving colleges and those serving universities. There was a reversal of the 1995 proportions, with the majority of responses in 2000 coming from university libraries. Table 2 shows the proportions of respondents from libraries serving various student population sizes. The majority of responses are from libraries serving fewer than 10,000 students.

\section{Instruction: Content and Methods}

The resources for which instruction is provided are noted in table 3 . The general trend seems to be that fewer libraries in the year 2000 offer instruction for the resources listed than was the case in 1995. A significant drop may be noted for instruc- 
tion on print indexes and other print materials. Table 4 shows responses that detail the instructional methods used. Fewer classroom lectures and demonstrations, self-paced library tours, essay

\begin{tabular}{|lcc|}
\hline \multicolumn{3}{|c|}{ TABLE 1 } \\
Type of Institutions Responding to Survey \\
\hline \hline Type of Institution & Proportion of Respondents (\%) \\
& $\mathbf{1 9 9 5}$ & $\mathbf{2 0 0 0}$ \\
\hline College or technical institution & $52.4^{*}$ & 43.0 \\
University & 47.6 & 55.6 \\
& & \\
*Combined categories of community college, community college/ \\
university, and college affiliated with a university.
\end{tabular}
workshops, posters, and videos were apparent in 2000 than was the case previously. Conversely, there appears to be an increase in the use of handson instruction in computer labs and in computer-assisted instruction (CAI). The U.S. data suggest that two percent of libraries in 1995 had a required credit course and that 30 percent offered a credit course, a proportion significantly larger than is the case in Canada. Overall, similar proportions of libraries in Canada and the U.S. use the various methods listed in table 4 . Surprisingly, one exception is that more Canadian libraries are using CAI (12\% of U.S. and nearly $30 \%$ of Canadian libraries in 1995 , and $36 \%$ of Canadian libraries in 2000). ${ }^{4}$ The reasons for this difference are unknown.

There has been a significant change over the past five years in student access to databases outside the library and to the Internet in general. In 1995, 53.7 percent of the surveyed libraries provided access to external networks and 68.9 percent provided access to the Internet, whereas in $2000,86.5$ percent of responding libraries provided access to outside networks and 97.1 percent provided access to the Internet.

\section{Libraries' Investment in Instruction}

Interestingly, there has been a slight decline in the proportion of respondents who indicated that they provide formal instructional activities $(79.1 \%$ in 1995 , and $77.4 \%$ in 2000). Also noted was a decline in the proportion of libraries that formally record their instructional objectives $(27.8 \%$ in 1995 , and $21.2 \%$ in 2000). Placing primary responsibility for instruction with a dedicated instructional librarian also seems to be on the decline: 7.9 percent of libraries in 1995 reported that this was the case for their institution, as compared to only 6.3 percent of libraries in 2000. Reference librarians have responsibility for instruction in 69.1 percent of libraries in 2000, down from 72.6 percent in 1995 . Other library staff members, mostly technicians, were given responsibility for instruction in 20.7 percent of libraries in 1995 but now are given this responsibility in 40.6 percent of libraries. This suggests a remarkable displacement of responsibility for instruction from professional librarians to technicians. As is the case in Canada, most academic libraries in the United States appear to place responsibility for instruction with the reference department. Indeed, only 11 percent of U.S. librar-

TABLE 2 Size of Institutions Responding to Survey

\begin{tabular}{lll} 
Size of Institution & $\begin{array}{c}\text { Proportion of Respondents (\%) } \\
\mathbf{1 9 9 5}\end{array}$ & $\mathbf{2 0 0 0}$ \\
\hline Fewer than 10,000 FTE students & 56.6 & 60.6 \\
10,000-20,000 FTE students & 21.4 & 18.7 \\
More than 20,000 FTE students & 22.0 & 20.7
\end{tabular}

ies have established a separate administrative unit for instruction. ${ }^{5}$ Moreover, there tends to be an ad hoc approach in larger U.S. institutions, with instructors delivering in- 


\begin{tabular}{|lcc|}
\hline \multicolumn{3}{|c|}{ TABLE 3 } \\
\multicolumn{3}{|c}{ Resources for which Instruction is Provided } \\
\hline \hline & Proportion of Respondents (\%) \\
Resource & $\mathbf{1 9 9 5}$ & $\mathbf{2 0 0 0}$ \\
\hline Catalog & 90.7 & 89.9 \\
Library use in general & 92.0 & 85.1 \\
Internet/Web & $52.5 *$ & 84.1 \\
CD-ROM indexes & 86.4 & 79.3 \\
Other print materials & 73.5 & 59.1 \\
Print indexes & 76.5 & 45.7 \\
Classification system & 50.0 & 40.9 \\
Government documents & 35.8 & 31.7 \\
Audiovisual materials & 21.6 & 16.8 \\
*Phrased as "other databases accessible outside the institution \\
(e.g. Internet)."
\end{tabular}

instruction. The largest proportion of libraries $(54.7 \%)$ allocates between one and five hours per week to instructional activities during the year, apart from the beginning of the academic year.

Financial support for instructional activities in libraries appears to be increasing. Distinct and dedicated funding for instruction in library budgets has doubled since 1995, when only 5.6 percent of libraries reported dedicated funding, to 11.1 percent today. However, struction individually and little overall coordination. ${ }^{6}$

In 2000, libraries report that investment of staff time in instructional activities dropped significantly after the start of the academic year, when 35 percent of libraries report spending more than ten hours per week on instruction. During the remainder of the year, only 8.9 percent of libraries allocate that much staff time to even this increase remains very low. In contrast, the levels of nonfinancial support (e.g., administrative support, recognition, encouragement) remain approximately the same. In 2000, 56 percent of respondents report that they experience "full support," 25.5 percent experience "moderate support," 13 percent experience "very little support," and 5.5 percent experience "no support." It seems re-

\section{TABLE 4}

\section{Instructional Methods}

\section{Method of Instruction}

Method of Instruction
Group instruction for specific courses or subjects
Individualized instruction
Group library tours
Classroom lectures, demos
Pathfinders or subject guides
Hands-on instruction in lab
Library guides/handbooks
Computer-assisted instruction
Self-paced library tours
Noncredit course
Additions to course notes for distance students
Essay assistance/workshops
Workbook program
Posters
Credit course
Video

Proportion of Respondents (\%) 2000

$\begin{array}{cc}\mathbf{1 9 9 5} & \mathbf{2 0 0 0} \\ \text { Not asked } & 88.9 \\ 86.4 & 82.2 \\ 84.0 & 80.3 \\ 72.2 & 66.3 \\ 68.5 & 64.9 \\ 43.2 & 63.9 \\ 69.1 & 63.5 \\ 29.6 & 35.6 \\ 22.8 & 13.9 \\ 15.4 & 13.0 \\ \text { Not asked } & 12.5 \\ 21.6 & 11.1 \\ 8.0 & 11.1 \\ 21.6 & 9.6 \\ 9.9 & 8.7 \\ 17.3 & 4.3\end{array}$




\begin{tabular}{|l}
\multicolumn{3}{|c|}{ TABLE 5 } \\
Mean Importance Rank for User Education Objectives \\
Reported by Respondents
\end{tabular}

markable that this generation would have any libraries that provide very little or no support for instructional activities.

Publicity for instructional activities remains similar to that reported in the first survey. In 2000, 71.2 percent of libraries send notices to faculty, 44.7 percent use posters, 42.3 percent advertise on the Web, and 34.6 percent place notices in the campus newspaper.

Those groups that are a focus of instruction have changed little over the past five years. First-year students are a focus of instruction at 84.6 percent of libraries, undergraduates at 59.1 percent of libraries, and returning adult students at 40.4 percent of libraries. An exception to the trend of little change is the attention devoted to teaching staff (faculty). In 1995, only 34 percent of libraries focused instructional efforts on faculty, but by 2000, this effort had increased to 46.6 percent of libraries. The estimated proportion of students reached by instructional efforts changed little, although there was a slight increase in the proportion of libraries indicating that they now reach 76 to 100 percent of their students $(18.1 \%$ of respondents in 1995 compared to $23.2 \%$ in 2000). Thus, although these are just estimates, it may be that greater numbers of students are receiving some instruction from their campus library.

\section{Instructional Objectives}

When respondents were asked to rank their current instructional objectives, the order of importance remained identical to that expressed in the 1995 survey (table 5). Teaching clients to find information in various sources continues to be the primary objective of instruction in Canadian academic libraries. Interestingly, the standard deviations (SDs) of the assigned ranks are lower for the 2000 survey, suggesting a greater degree of agreement among respondents about the relative rank of each objective. When respondents were asked what their preferred instructional objectives would be, again, the rank order remained the same for both surveys (table 6). Teaching general research strategies is the preferred first objective. Again, the SDs of the assigned ranks are less than they were for the 1995 data, implying greater agreement among respondents about the relative rank of objectives.

Respondent comments about how instructional priorities have changed over the past five years reveal an increased emphasis on "conceptual skills" and a move "from emphasis on specific sources to [an] emphasis on underlying structures with the idea being that skills will be transferable." Another respondent noted that "we are concentrating on trying to 
teach structure and research strategies rather than concentrating on specific databases," a view echoed by several other commentators. One noted that it is now "more important that students understand [the] research process." Likewise, many respondents noted that "critical evaluation has become more of an issue." The latter change has occurred because "in past years, the library collection was the main focus and we know those materials were 'good' because they were purchased based on reviews and faculty recommendations." This respondent has identified the key reason why critical thinking and evaluation have gained such prominence recently, because surely this was equally important when dealing with paper-based information. What has changed is that when resources were housed within the boundaries of a library, they were filtered; librarians had previously evaluated and purposefully selected these resources as worthy and potentially useful. Now that many resources are available directly to clients online, critical evaluation skills must be taught more deliberately.

\section{Evaluation}

Respondents appear less confident in 2000 that they meet their instructional objectives, whether or not their objectives are recorded formally. In 1995, 61.3 percent of respondents reported that they believe they meet their objectives, compared to 52.7 percent in 2000 .

Trends in evaluation have changed little over the five-year period. In 2000, 76 percent of respondents report that they do informal evaluations with teaching faculty (a slight increase from $70.6 \%$ in 1995); 70.2 percent do informal evaluations with students (compared to $71.9 \%$ in 1995); 41.3 percent do self-evaluation (compared to $40.6 \%$ in 1995); 34.6 percent administer feedback questionnaires to students (a decline from $39.4 \%$ in 1995$) ; 25.5$ percent actually test students on their knowledge (compared to $26.3 \%$ in 1995); and 16.3 percent send feedback questionnaires to faculty (an increase from 10.6\% in 1995).

\section{Information Literacy}

The terms bibliographic instruction (BI), user education, and information literacy instruction often are used interchangeably, despite conceptual differences (i.e., BI and user education are associated more closely than information literacy instruction with training in the use of library resources and structures). Thus, the survey sought to clarify respondents' understanding of information literacy. Table 7

\begin{tabular}{|c|c|c|}
\hline \multicolumn{3}{|c|}{$\begin{array}{c}\text { TABLE } 6 \\
\text { Preferred Mean Importance Rank for User Education Objectives } \\
\end{array}$} \\
\hline \multirow[b]{2}{*}{ Objective of User Education } & \multicolumn{2}{|c|}{$\begin{array}{l}\text { ferred Mean Rank in Importance } \\
1 \text { = highest rank }\end{array}$} \\
\hline & 1995 & 2000 \\
\hline Teach students general research strategies & $1.9\left(\mathrm{SD}^{*}=1.46\right)$ & $2.1(\mathrm{SD}=1.24)$ \\
\hline $\begin{array}{l}\text { Teach students how to find information in } \\
\text { various sources }\end{array}$ & $2.0(\mathrm{SD}=1.54)$ & $2.4(\mathrm{SD}=1.25)$ \\
\hline $\begin{array}{l}\text { Teach students how to critically evaluate the } \\
\text { quality and usefulness of information }\end{array}$ & $2.5(\mathrm{SD}=1.89)$ & $2.7(\mathrm{SD}=1.40)$ \\
\hline Teach students how to locate materials in the library & $2.6(\mathrm{SD}=2.07)$ & $3.5(\mathrm{SD}=1.75)$ \\
\hline $\begin{array}{l}\text { Teach students how databases in general } \\
\text { are structured }\end{array}$ & $3.5(\mathrm{SD}=2.27)$ & $4.4(\mathrm{SD}=1.46)$ \\
\hline Teach awareness of technological innovations & $3.7(\mathrm{SD}=2.36)$ & $5.1(\mathrm{SD}=1.20)$ \\
\hline
\end{tabular}




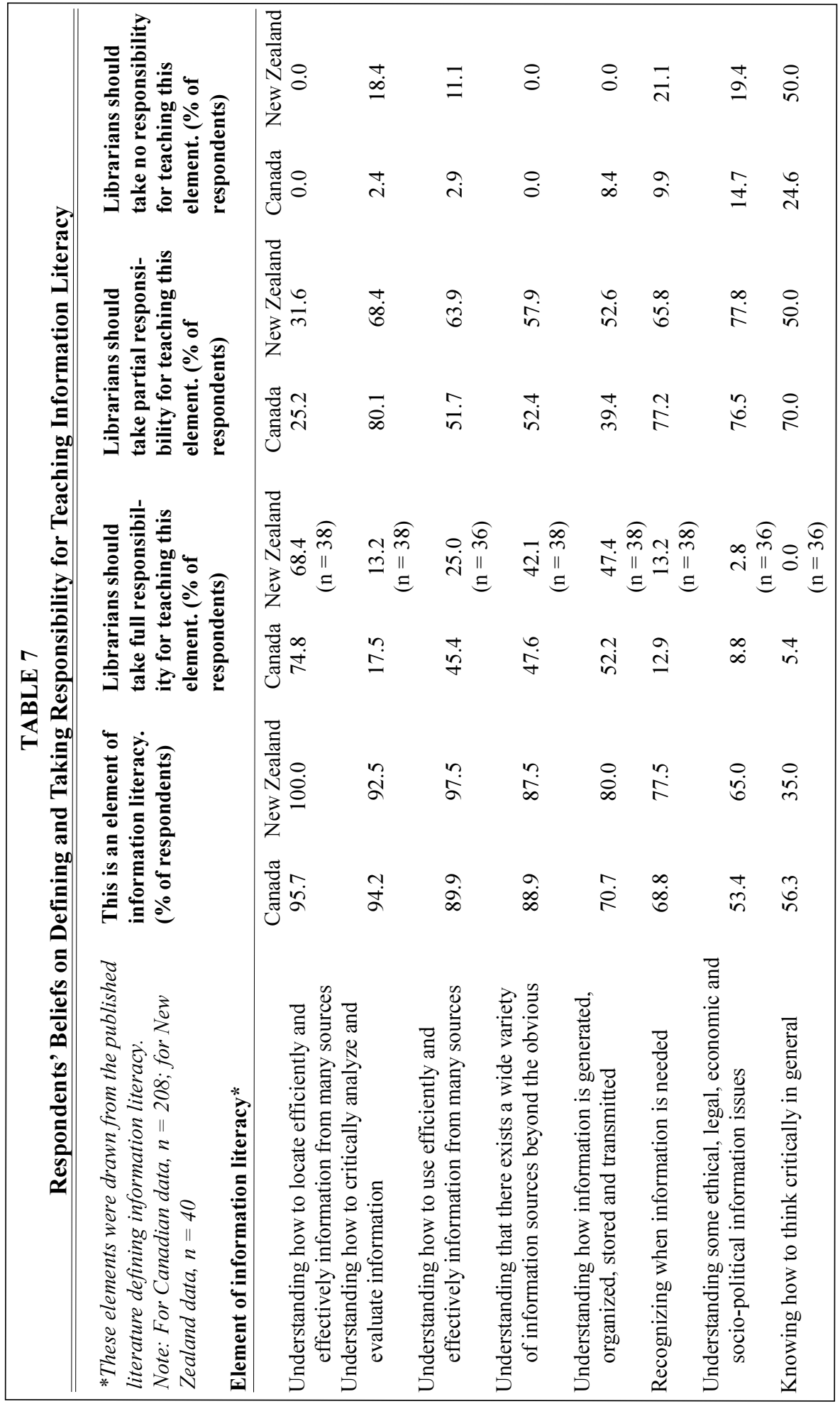


shows how respondents define the term and illustrates their opinions about the degree of responsibility that academic libraries ought to take for instruction in the various elements that constitute information literacy. In addition, it offers comparisons with data from the New Zealand survey. ${ }^{7}$ Data on understanding information literacy were not collected in the 1995 Canadian survey, so longitudinal comparisons cannot be made. ${ }^{8} \mathrm{Al}-$ though a majority of Canadian respondents agree that each of these elements is a part of information literacy, few agree on who bears responsibility for instructing each element. Indeed, one respondent wrote in a marginal note: "What library would admit to no responsibility in any of these areas?" However, only two of the elements (teaching "understanding how to locate efficiently and effectively information from many sources" and teaching "understanding how information is generated, organized, stored, and transmitted") are viewed by a majority of Canadian respondents as being the full responsibility of academic libraries. For teaching six of the eight elements, however, respondents feel partial responsibility. Respondents cited teaching faculty as the other primary group responsible for teaching information literacy but also mentioned a role for students themselves, teaching assistants, campus computing centers, parents, school librarians, and public school teachers. One respondent noted in a marginal comment:

I think that responsibility for all of these should be shared between librarians and the teaching faculty. No library and its contents can be an island unto itself, nor can a teacher effectively teach without the support of external information. Students themselves also have to take responsibility for their learning. Consider it a symbiotic relationship between librarian, instructor, and student-where each benefits from the other.
Despite the emphasis in information literacy literature on critical thinking ( $c f$. Sonia Bodi, 1988; Eugene Engeldinger, 1988; Chris Atton, 1994; Craig Gibson 1995), nearly a quarter of Canadian respondents believe that librarians bear no responsibility for teaching clients how to think critically in general. ${ }^{9}$

\section{Relationships between Variables}

Chi-square tests were performed on some variables to seek significant differences based on the language of the institution (English or French), type of library (college or university), and size of library. A significant difference was found between English- and French-language libraries on several variables. For example, Englishlanguage libraries were more likely to offer formal instructional activities $\left(\mathrm{x}^{2}=\right.$ 19.52, df =1, p = .000; Cramer's V = .307). Moreover, English-language institutions were more likely to offer informal instruction $\left(\mathrm{x}^{2}=9.69, \mathrm{df}=1, \mathrm{p}=.007 ;\right.$ Cramer's V $=.216$ ). Statistically significant differences according to language also were noted for respondents' beliefs about the definition of information literacy. English-language respondents were more likely to indicate that "recognizing when information is needed" is an element of information literacy $\left(x^{2}=14.62, \mathrm{df}=1, \mathrm{p}=.000 ;\right.$ Cramer's $\mathrm{V}=.266)$. Similarly, these respondents were more likely to indicate that "understanding some ethical, legal, economic, and socio-political information issues" is an element of information literacy $\left(\mathrm{x}^{2}=\right.$ 4.44, $\mathrm{df}=1, \mathrm{p}=.049 ;$ Cramer's V = .146) and that "understanding that there exists a wide variety of information sources beyond the obvious" is an element of information literacy $\left(\mathrm{x}^{2}=4.94, \mathrm{df}=1, \mathrm{p}=.04\right.$; Cramer's V = .155). Finally, English-language respondents were more likely to believe that "understanding how to use efficiently and effectively information from many sources" is an element of information literacy $\left(\mathrm{x}^{2}=9.91, \mathrm{df}=1, \mathrm{p}=\right.$ .004 ; Cramer's V = .219) and that "knowing how to think critically in general" is an element of information literacy $\left(\mathrm{x}^{2}=\right.$ $8.32, \mathrm{df}=1, \mathrm{p}=.004$; Cramer's V = .200). 
Beliefs about academic libraries' degree of responsibility for teaching some elements of information literacy also varied significantly by language. For instance, English-language respondents were more likely to believe that libraries bear only partial responsibility for teaching students about "understanding how to use efficiently and effectively information from many sources" $\left(\mathrm{x}^{2}=10.78, \mathrm{df}=\right.$ $2, \mathrm{p}=.005$; Cramer's V = .229). The reasons for these differences by language of institution are unknown; explication of these differences would be a matter for future research.

The majority of comments indicated that the primary change was a move from instructor-led demonstrations to hands-on instruction in a computer lab.

Significant relationships also were found between type of institution (college/university) and a number of other variables. For instance, university libraries are more likely to offer formal instruction $\left(\mathrm{x}^{2}=6.41, \mathrm{df}=2, \mathrm{p}=.041 ;\right.$ Cramer's V $=.176)$. Similarly, respondents from university libraries are more likely to believe that "recognizing when information is needed" is an element of information literacy $\left(x^{2}=11.06, d f=2, p=.004\right.$; Cramer's $\mathrm{V}=.231$ ). Respondents from university libraries also are more likely to believe that academic libraries bear at least partial responsibility for teaching "recognizing when information is needed" $\left(\mathrm{x}^{2}=\right.$ 10.29, $\mathrm{df}=4, \mathrm{p}=.036$; Cramer's V = .160).

Not unexpectedly, a statistically significant relationship exists between type of institution and size of institution $\left(\mathrm{x}^{2}=\right.$ $64.83, \mathrm{df}=4, \mathrm{p}=.000$; Cramer's $\mathrm{V}=.400$; i.e., university libraries serve significantly larger populations than do college libraries). Therefore, it is not surprising that statistically significant relationships would be found between institution size and these same variables. Indeed, libraries serving student populations of 10,000 to 20,000 are significantly more likely than expected to report that "recognizing when information is needed" is an element of information literacy $\left(\mathrm{x}^{2}=10.32\right.$, $\mathrm{df}=2, \mathrm{p}=.006$; Cramer's V = .225), and libraries serving populations greater than 20,000 are significantly more likely than smaller libraries to include "understanding some ethical, legal, economic and socio-political information issues" as an element of information literacy $\left(x^{2}=6.80\right.$, $\mathrm{df}=2, \mathrm{p}=.033$; Cramer's $\mathrm{V}=.183$ ).

\section{Effects of Technological Change}

Respondents were asked to what degree they believe that technological change has affected both the delivery and the content of instruction. In 2000, the number of respondents indicating that technology has affected instructional delivery "not at all" or "slightly" decreased (12.9\% compared to $23.9 \%$ in 1995), whereas the proportion of respondents indicating "a great deal" of influence on delivery increased (48.6\% compared to $40.9 \%$ in 1995). The influence of technological change on the content of instruction has remained fairly constant, with 2.4 percent of libraries reporting in 2000 that they notice no influence, 13.5 percent noting only a "slight" influence, 44.7 percent noting "quite a bit" of influence, and 37 percent noting "a great deal" of influence. This range of responses also can be reflected in the variety of positive, negative, and ambivalent comments expressed by U.S. respondents to the LOEX survey..$^{10}$ Indeed, the comments quoted in the U.S. survey report echo to a large degree those provided by the Canadian respondents below.

Respondents who indicated that information technology had changed the way they delivered instruction also were asked to provide, via open-ended written comments, examples of such change. The majority of comments indicated that the primary change was a move from instructor-led demonstrations to hands-on instruction in a computer lab. For libraries without a computer lab, instructional delivery moved from static overhead presentations to more dynamic online presentations, using PowerPoint ${ }^{\mathrm{TM}}$ and realtime Web access. One respondent wrote: 
More reliable networking capacity and more network drops in our building make for greater confidence level. [We are] less wary of technology than in previous years, more confident because technology actually works now. [We have] better infrastructure, thanks in large part to grants to improve instructors' access to technology.

Likewise, respondents who indicated that information technology had changed the content of their instruction were asked to provide examples of such change. Open-ended written comments suggested that instruction now includes "a wider range of tools and formats" and that the emphasis now is "on Web-based resources, Internet resources, [and] critical evaluation skills." Traditional content has been "added [to] in terms of [the] quantity of what is taught and complexity (e.g., different search platforms, electronic products)." One respondent summed up these changes by noting that now "less time is spent on content and quite a bit on 'how to.'” This sentiment was echoed by another respondent who noted that:

far more time is spent explaining the technical or mechanical operations: how to access electronic indexes and full-text materials-not to mention how to download, e-mail and print from these sources, all of which 'do things' differently. This is somewhat at the expense of how to find information; but for the most part, we have dealt with this by lengthening the sessions.

Naturally, these changes mean that instructors now "have to understand [their] own internal networks, servers and budgets." However, another respondent wrote that in her library, "we teach more about concepts and less about button pushing or page turning."

The increased emphasis on evaluation was interesting to note. One respondent wrote: "[Now there is] more emphasis on evaluation of sources, more emphasis on transferable information literacy skills, [and] more computer/technical skills taught." These changes in instructional content may come as a surprise to some students. One respondent reported that "a comment on a recent library instruction [evaluation form] stated 'Why is the LIBRARY [sic] demonstrating what we can find on the Internet[?]' They don't understand 'Internet' is how we now deliver our journals, our reference materials, almost everything."

Another respondent indicated that:

It has become imperative to discuss critical, ethical, legal and moral issues because of the lack of control over 'published' information on the Internet. Whether we want to or not, librarians must give a crash course on logic and critical analysis-because we can longer evaluate or 'select' resources for our patrons. Students are in over their heads, have way too much information and need to be 'guided' through the maze.

When asked whether they believe that technological change has increased participation in instruction, the respondents' responses from the 1995 and 2000 surveys are much the same (73\% in 1995 and $75 \%$ in 2000 report yes). However, there seems to be slightly less enthusiasm for the possibility that technological change has improved instruction. In 1995, 67.5 percent of respondents indicated that this was the case, compared to only a slight increase to 72.1 percent in 2000 .

Written comments noted the reasons for increased interest on the part of students. Instruction is now "more visually attractive, [and] has made student research more productive/successful. Also many students feel stressed by rapidly changing technology and participating in instruction helps them 'keep up.'" In addition, many respondents noted that instruction is now "more dynamic and pre- 
cise" as well as "engaging." "Hands-on instruction has made sessions more interactive." "Anything that can be 'hands on' is more interesting than the old 'building' tours." Students, noted respondents, "respond very well to the technology. It's a faster-paced presentation and more professional in appearance." Students now "see the relevance of library instruction." Several respondents noted that "if it's on a computer, it's sexy. Books are boring!" One commented that "electronic tools are 'sexy', faster, [and that] interest = intimidation = participation."

Respondents also supported their beliefs as to whether information technology has improved instruction, commenting that current efforts are now "more dynamic and powerful," "you can reach more students with more resources," and "if students are more interested and participate more readily, then I think they are absorbing more information as well." New technologies also have helped some respondents reach distance learners more effectively. Delivery of instruction is more efficient and relevant, less theoretical, and more customizable (individualizable) in general, it was reported; and technology has provided "more opportunities to stress critical thinking" and "higher level skills." Despite this assertion, however, some respondents recognize that critical thinking skills are independent of technology: "The most important content is teaching critical research skills which are independent of the particular technology in many ways."

Technological change also has provided network connections that allow instructors "to answer database questions 'on the fly,' [so instruction] can be more spontaneous and more relevant." Instructors now can "reach different kinds of learners (not just auditory learners)," and students have a greater "ability to see the steps involved [in research]." Another respondent disagreed, arguing that "with [the] focus on technology, there is less time to devote [to] talking about strategy, [the] nature of information sources, etc." On the downside, despite increased stu- dent interest and participation, there is occasionally "great frustration on everyone's part when the hardware or software doesn't work!" Another respondent noted that "the downside is that people can get interested in the technology rather than the content." Several respondents commented that "instruction is different, not necessarily better." A thoughtful summary comment noted that:

I think IT achieves some efficiencies (e.g., modular development) and economies of scale (can deliver to more students) which theoretically should free us to focus on pedagogical development. Are there enhanced outcomes? There is no evidence yet to support this.

Improved instruction has led to other changes for librarians: Instructors have to be "better prepared," "we have had to sharpen our tools ... and our skills in teaching the use of this plethora of resources." Other comments included: "real-time demonstrations and subsequent practice in [the] student lab means fewer basic questions are asked and the questions that do come up are more logical and pertinent than without hands-on experience," and "more students come to [the] library for follow up assistance."

\section{Barriers Faced by Instructors}

Two final open-ended questions were included on the survey instrument. The first asked respondents to identify the barriers they face as they provide instruction, and the second asked for general comments about instruction. Overwhelmingly, respondents indicated that their primary barriers fall into two categories: limited resources (staff, time, and equipment/facilities related), and the difficulties encountered with faculty and student attitudes that hinder positive relationships with librarians and impede effective instruction. Of the 164 respondents to this question, 46.3 percent specifically mentioned difficulties with faculty (fac- 
ulty not valuing information literacy instruction); 40 percent commented on the lack of appropriate, up-to-date equipment and space for instructional purposes; 39.6 percent mentioned the lack of time for planning and delivering instruction; 31.7 percent cited insufficient staff to meet instructional demands; and 26.8 percent reported issues relating to student attitudes toward libraries and librarians that impede instructional effectiveness. Curiously, a significant difference was found between English- and French-language institutions on the degree to which a lack of equipment and facilities acts as a barrier to instruction: respondents from English-language libraries were significantly more likely to comment on this problem $\left(\mathrm{x}^{2}=6.02, \mathrm{df}=1, \mathrm{p}=.014\right.$; Cramer's $\mathrm{V}=.171)$. It also is apparent that many library instructors believe that access to appropriate instructional space must be available in the library, which actually may not be required when most resources demonstrated are electronic in nature. In addition, where other instructors generally are accustomed to traveling to various buildings and classrooms on the campus to do their teaching, librarians appear to remain tied to their familiar physical locations.

As one respondent wrote:

\begin{abstract}
[Barriers include] lack of interest from students in formal instruction, faculty not encouraging their students to take advantage of instruction, lack of suitable facilities (e.g., we have a small library and just use our public terminals for instruction thus limiting the number of students and inconveniencing other users).
\end{abstract}

Another telling comment was: “TIME [sic] to prepare adequately, equipment that breaks down ... no BI classroom with computers even though we've been asking for eight years!, BURNOUT [sic]." Students' attitude problems attributed by respondents included apathy, misconceptions about the availability of information on the Web, misconceptions about their expertise in searching for and evaluating electronic information, and "low expectations of [the] library and librarians." Barriers relating to faculty focused on their reluctance to share instructional time and their unwillingness to recognize that librarians have instructional capabilities and useful skills to teach. One respondent noted facing a "lack of credibility ascribed by the faculty to this function." Another wrote: "Librarians at our institution are not seen as partners in the teaching process ... faculty take us for granted and do not share information." Several respondents suggested that faculty lack skills themselves: "If faculty members don't know how to use libraries and information resources, they do not give their students appropriate assignments and do not actively encourage their students to gain these skills." These sentiments were echoed in the following comment: "Some [faculty] will not arrange for library instruction, will not check to see if resources are in the library, will not inform us of their assignments or return calls (assume we can teach by osmosis)."

General comments also picked up on some of the earlier themes. One respondent noted that "library instruction would be improved by greater integration with classroom work [and] greater integration with instruction by teaching faculty." On campuses where this integration is occurring, positive benefits are accruing:

Because they are already so busy, students will not come to workshops in the library if they are voluntary. The best thing for us has been to work with faculty to make the information literacy component a required assignment, usually tied to a research paper assignment that already exists in their courses. Students see the direct relevance of the instruction. They come to library workshops out of a felt need. Faculty are enthusiastic because they don't have to do any extra marking 
(librarians just submit the marks to them). A fully curriculum-integrated programme of information literacy works better for our students than a separate (voluntary) course, whether for credit or noncredit.

Many respondents echoed this emphasis on the need for curriculum integration. However, other campuses seem to have some way to go: "We have managed to increase participation levels by aggressive promotion and then delivering the goods. Overall, though, we feel we still miss too many potential people who need help," noted one respondent. Another wrote: "Support is getting better, but we are strong advocates, as are the learners, for more time for research instruction." At a different campus, there is:

very positive attention and focus within the University community on creating a good environment for teaching and learning ... there is active pursuit of partnerships among service providers and administration to provide instructional support. Library staff are actively engaged in developing and promoting their teaching role in the University community.

Elsewhere, there is less enthusiasm: "Instruction is not promoted as the library can barely handle the present level of instruction," and "with only one librarian providing instruction we have reached the limit of what we can offer. More personnel and support are required, plus an understanding on the part of the university administration and academic realm as to the necessity of the endeavor."

Another respondent wrote that instruction "has suffered drastically from downsized staff/budgets at a time students need more attention because of technology - they are required to use electronic resources but are often not taught how. We know there is a widening gap between what is expected and the sup- port provided, and know there is a role for the library which we have stopped performing."

A similarly unfortunate comment stated: "I see instruction as being perceived as even less important than it was ten years ago. The speed and ease of Web technology obscures the need for learning searching and evaluating skills." A similar comment indicated that the respondent was "underutilized and undervalued." Another wrote:

the irony of a Master in Library Science is that Instruction is not part of the curriculum. Some of the best instruction will come from those who have already taught. It is difficult for instructional classes in libraries to be taken seriously if the person is not trained in teaching and is not comfortable or effective at classroom delivery.

Respondents clearly identified areas needing improvement. As one commented, "We need to write a library instruction goals document, agree on standards, and test for results." Blame was laid elsewhere, too:

Fighting the 'instant gratification' of audio-visual junior students. Brightly colored hair, skateboards and attitude. 'Entertain me' is all they seem to care about. Only very slick presentations impress them, they have an appalling lack of interest in the content. When most library journals, reference materials, and databases are delivered over the Web, a huge problem are these young students who think they know anything and everything on the Web.

Although the LOEX survey did not specifically report a similar concern with faculty and student attitudes, the U.S. respondents clearly indicated that resource restrictions were a significant barrier to their instructional efforts. ${ }^{11}$ 


\section{Conclusions}

The data obtained in the current Canadian survey raise several questions. And for those interested in improving instruction, they present some significant concerns. For example, does the apparent trend to replace professional MLIS-trained librarians with library assistants for instructional purposes portend a de-professionalization of instruction? Is such a question even appropriate in light of the general lack of training for instruction provided to professional librarians during their MLIS degrees? This question is related to the continuing lack of attention paid to other aspects of instruction. Although there are obvious examples where instructors have taken responsibility for learning how to teach well, and where libraries have devoted significant resources to the instructional function, there is a remarkable level of apparent neglect for instruction in Canadian academic libraries. This neglect, perhaps unavoidable in the context of budget restraints, must influence the attitudes of faculty and students on campus toward libraries' instructional efforts. Does the continuing lack of formally recorded instructional objectives, in combination with a lack of dedicated funding and formal evaluation mechanisms, bode well for the success of information literacy instruction? This author has explored this question elsewhere but it continues to dog this critical area of service. ${ }^{12}$

That these findings remain relatively constant seems noteworthy in light of the apparent emphasis on information literacy on the ACRL Web page (http:// www.ala.org/acrl/). It must be noted that a similar emphasis is not evident for the Canadian Association of College and University Libraries, although this body does have an interest group devoted to instructional concerns. If instructional librarians would like their efforts to be taken seriously and valued on campus, there must be a clear demonstration that information literacy instruction is resourced adequately, has been well planned, is delivered by trained instructors, and has positive and practical outcomes for clients. Although these outcomes may seem obvious to librarians, they appear not to be perceived by faculty and students, at least on many campuses. The nature and extent of such outcomes are being pursued in the next phase of this study.

\section{Notes}

1. Heidi Julien and Gloria J. Leckie, "Bibliographic Instruction Trends in Canadian Academic Libraries," Canadian Journal of Information and Library Science 22 (July 1997): 1-15.

2. Heidi Julien, “User Education in New Zealand Tertiary Libraries: An International Comparison," Journal of Academic Librarianship 24 (July 1998): 301-10.

3. Linda Shirato and Joseph Badics, "Library Instruction in the 1990s: A Comparison with Trends in Two Earlier LOEX Surveys," Research Strategies 15, 4 (1997): 223-37.

4. Ibid., 230.

5. Ibid., 228.

6. Ibid.

7. Julien, "User Education in New Zealand Tertiary Libraries."

8. Julien and Leckie, "Bibliographic Instruction Trends in Canadian Academic Libraries."

9. Sonia Bodi, "Critical Thinking and Bibliographic Instruction: The Relationship," Journal of Academic Librarianship 14 (July 1988): 150-53; Eugene Engeldinger, "Bibliographic Instruction and Critical Thinking: The Contribution of the Annotated Bibliography," RQ 28 (winter 1988): 195202; Chris Atton, "Using Critical Thinking as a Basis for Library User Education," Journal of Academic Librarianship 20 (Nov. 1994): 310-13; Craig Gibson, "Critical Thinking: Implications for Instruction," RQ 35 (fall 1995): 27-35.

10. Shirato and Badics, "Library Instruction in the 1990s," 236.

11. Ibid.

12. Julien, "User Education in New Zealand Tertiary Libraries." 